\title{
On the Frequency Limit and Phase of Outer Hair Cell Motility: Effects of the Membrane Filter
}

\author{
J. Santos-Sacchi \\ Sections of Otolaryngology and Neurobiology, Yale University School of Medicine, New Haven, Connecticut 06510
}

\begin{abstract}
Whole-cell voltage clamp and displacement-measuring photodiode techniques were used to study electrophysiological and mechanical properties of the guinea pig outer hair cell (OHC). OHCs demonstrate a voltage-mechanical response (V-M) function that can be fit by a two state Boltzmann relation, where the cell normally rests near the hyperpolarizing saturation region $(-70$ to $-90 \mathrm{mV})$. The voltage at halfmaximal length change $\left(V_{h}\right)$ is depolarized relative to the resting potential, and this ensures that for symmetrical sinusoidal voltage stimulation about the resting potential, AC and DC mechanical responses will be generated. Analysis of OHC motility using pure tone voltage bursts from 11 to $3200 \mathrm{~Hz}$ demonstrates both $A C$ and DC mechanical responses. By exploiting the frequency-dependent currentvoltage phase separation that is characteristic of an RCdominated system under voltage clamp, it is demonstrated that OHC motility follows the phase of AC transmembrane voltage and not that of current. For voltage stimulation across frequencies in the acoustic range, the motility cutoff frequency corresponds to the cutoff frequency of the imposed transmembrane voltage. Frequency cutoffs approaching 1 $\mathrm{kHz}$ have been measured but are clamp time constant limited. These observations are congruent with the voltage dependency hypothesis of OHC motility. In addition, the DC component of the mechanical response is shown to be frequency independent, but to decrease in magnitude disproportionately compared to the AC component as the magnitude of the driving voltage decreases. This is predicted from the form of the $V-M$ function, whose level dependent DC nonlinearity is a consequence of the resting potential being displaced from $\boldsymbol{V}_{n}$. The net effect is that the mechanical DC: AC ratio approaches zero for small AC voltages. Taken together, these findings question the ability of the $\mathrm{OHC}$ mechanical response to influence organ of Corti micromechanics at high acoustic frequencies where a tuned amplification of basilar membrane motion is hypothesized.
\end{abstract}

Hair cells transduce mechanical stimuli into electrical signals by modulating a standing transduction current in response to stereocilia displacement; this current induces a receptor poten-

\footnotetext{
Received Oct. 1, 1991; revised Dec. 13, 1991; accepted Dec. 18, 1991.

This work was supported by an NIDCD Research Career Development Award and NIH Grant DCO0273. I thank Jack Callahan and Janet Santos for technical assistance, and Dr. Jont Allen for many helpful discussions. I also thank Drs. Yukihiro Sato, Lisa Olson, Paul Manis, and Mike Zidanic for comments on early versions of the manuscript. Portions of this work were completed at NJ Medical School.

Correspondence should be addressed to Joseph Santos-Sacchi, Ph.D., Department of Surgery, Section of Otolaryngology, Yale University School of Medicine BML 244, 333 Cedar Street, New Haven, CT 06510.

Copyright (c) 1992 Society for Neuroscience 0270-6474/92/121906-11\$05.00/0
}

tial across the basolateral membrane of the cell, the depolarizing phase of which may promote the release of neurotransmitter (Hudspeth, 1989). Although evidence had accumulated that some type of interaction between outer (OHCs) and inner hair cells (IHCs) of the organ of Corti promoted the highly selective and sensitive responses of the mammalian auditory system to highfrequency acoustic stimulation (Dallos and Harris, 1978; Harrison and Evans, 1979; Brown and Nuttall, 1984), a potential mechanism for such an interaction remained obscure until recently. Following the discovery that the $\mathrm{OHC}$ is capable of electrically evoked mechanical responses (Brownell et al., 1985), a reevaluation of the classical concepts of mammalian hearing has been underway. Current theories concerning the basis of a cochlear amplifier envision an acoustically evoked cycle by cycle feedback process between OHC and basilar membrane (Geisler and Shan, 1990; Robles et al., 1991; Ruggero and Rich, 1991). That is, in vivo, the acoustically evoked electrical responses of the OHC should effect rapid length changes of these cells that modify the mechanical input to the IHC-the receptor cell that receives up to $95 \%$ of the afferent innervation (Spoendlin, 1988).

We have previously shown that under whole-cell voltage clamp, blocking the known ionic conductances of the OHC does not interfere with the cell's mechanical response, and we proposed that transmembrane potential was the driving force responsible for OHC motility (Santos-Sacchi and Dilger, 1988). Although the molecular basis of $\mathrm{OHC}$ motility remains to be determined, the physiological consequences of its voltage dependence are readily discernible. For example, the voltage dependence suggests that AC motility magnitude and phase characteristics should be governed by the attenuation effects of the $\mathrm{OHC}$ membrane (RC) filter. Any feedback contribution of the $\mathrm{OHC}$ to basilar membrane mechanics will be dependent upon these magnitude and phase characteristics. I report here that an analysis of $\mathrm{OHC}$ motility in response to step and $\mathrm{AC}$ voltage stimuli confirms the voltage dependency hypothesis, since the frequency extent and phase of motility are dependent upon the extent and phase of the imposed transmembrane voltage. Furthermore, while the effects of the membrane filter influence the AC mechanical component directly, the DC component is indirectly susceptible. Indeed, the DC component is far more susceptible than the $\mathrm{AC}$ component. These results are important for understanding the possible contribution of $\mathrm{OHC}$ motility in peripheral auditory processing.

Preliminary reports of this work have been presented previously (Santos-Sacchi, 1990, 1991a).

\section{Materials and Methods}

General. Guinea pigs were overdosed with pentobarbital. The temporal bones were removed, and OHCs were isolated nonenzymatically from 
the cochleas by gentle pipetting of the isolated top two turns of the organ of Corti. The cell enriched supernatant was then transferred to a $700 \mu \mathrm{l}$ perfusion chamber, and cells were permitted to settle onto the cover glass bottom. All experiments were performed at room temperature $\left(\sim 23^{\circ} \mathrm{C}\right)$. A Nikon Diaphot inverted microscope with Hoffmann optics was used to observe the cells during electrical recording. All experiments were taped with a Panasonic AG6300 video recorder. A modified Leibovitz medium $\left(\mathrm{NaCl}, 142.2 \mathrm{~mm} ; \mathrm{KCl}, 5.37 \mathrm{~mm} ; \mathrm{CaCl}_{2}, 1.25 \mathrm{~mm}\right.$; $\mathrm{MgCl}_{2}, 1.48 \mathrm{~mm}$; HEPES, $5.0 \mathrm{~mm}$; dextrose, $5.0 \mathrm{~mm}$; $\mathrm{pH} 7.2$ ) was used as the normal perfusate. Modifications to the extracellular medium are noted in figure captions, with $\mathrm{NaCl}$ adjusted to maintain osmolarity (300 mOsm). Extracellular solutions were changed via two methods. A chamber perfusion system permitted the fluid in the whole chamber to be constantly exchanged with fresh medium $(0.1-1 \mathrm{ml} / \mathrm{min})$. A more rapid and direct perfusion system was used to perfuse single cells selectively under voltage clamp, during continuous exchange of bulk medium via chamber perfusion. The device is a four-barreled glass pipette tapered to about $100 \mu \mathrm{m}$ and fitted with a polyethylene sleeve at the tip to permit fluid flow from a single port with a small dead volume. Solutions were fed to the pipette under gravity control and rapidly switched with solenoid valves. The tip of the pipette was brought to within $50 \mu \mathrm{m}$ of the cell being studied, and the flow of solution was adjusted so as not to perturb the cell physically.

Electrical recording. OHCs were whole-cell voltage clamped with a Dagan patch-clamp amplifier at holding potentials between -70 and $-80 \mathrm{mV}$, similar to potentials recorded in vivo (Dallos et al., 1982). Pipette solutions were composed of $140 \mathrm{mM} \mathrm{KCl}$ or CsCl, 5 or $10 \mathrm{~mm}$ EGTA, 2 mi $\mathrm{MgCl}_{2}$, and $5 \mathrm{~mm}$ HEPES buffered to pH 7.2. Gigohm seals were obtained at the nuclear level of the cell membrane, and electrode capacitance was compensated prior to whole-cell recording. Voltage step studies were performed with an Axolab $1100 \mathrm{~A} / \mathrm{D}$ and D/A board (Axon Instruments, Foster City, CA) with associated software (pCLAMP). AC studies were performed using a digital signal processing board with custom-written software (DSP-16; Ariel Corp., Highland Park, NJ) capable of delivering and analyzing pure tone or swept frequency stimuli. Data were saved to disk for off-line analysis.

For most experiments, ionic conductances were blocked. Under these conditions, the cell clamp can be modeled most simply as an electrode resistance $\left(R_{s}\right)$ in series with a parallel combination of the membrane resistance $\left(R_{m}\right)$ and capacitance $\left(C_{m}\right)$. These component values were estimated at the holding potential from current records in response to $-10 \mathrm{mV}$ voltage steps, and were accounted for during analysis, so that actual voltages imposed upon the cell are known (Marty and Neher, 1983). Care was taken to maintain low series resistance values during recording by delivering transient positive or negative pressure into the electrode to maintain an unobstructed orifice; electronic series resistance compensation was employed as well. The program CLAMPEX (Axon Instruments, Foster City, CA) was modified to provide a continuous display of clamp time constant, cell capacitance and resistance, and series resistance between data collections. The magnitude and phase of the transmembrane voltage $\left(V_{m}\right)$, predicted from the command voltage $\left(V_{c}\right)$, were obtained using the estimated component values by modeling the impedance $\left(Z_{\text {in }}\right)$ of the cell clamp with the software package MATLAB (Mathworks, Natick, MA):

$$
Z_{\text {in }}=R_{s}+Z_{m}
$$

where

$$
\begin{aligned}
Z_{m} & =\frac{R_{m}}{1+s C_{m} R_{m}}, \quad s=j \omega, \quad j=\sqrt{-1}, \quad \omega=2 \pi f ; \\
I & =V_{c} / Z_{\text {in }} \\
V_{m} & =I Z_{m} .
\end{aligned}
$$

In some cases, an absolute delay $\left(I=I \cdot e^{-s t}\right.$. where $t$ is the delay in seconds) was included in the model so that the predicted phase plots coincided (as determined by eye) with those of the measured current and mechanical response plots. Typically, this was required when series resistance compensation was used, and may be the result of delays introduced as a result of the compensation feedback.

OHC motility measures. OHC mechanical responses and currents were simultaneously measured in response to step or sinusoidal voltage stimuli. For steady state movements (voltage steps $>100 \mathrm{msec}$ ), length changes were analyzed off the video monitor during playback by placing differential optoresistors or a position-sensitive detector (Hamamatsu
Corp., $\mathrm{NJ}$; output filtered at $30 \mathrm{~Hz}$ ) across the image of the cuticular plate (apical end of the cell) at a monitor magnification of $2800 \times$ (Santos-Sacchi, 1989). Fast OHC movements elicited by voltage clamp with short-duration stimuli (below video detection) were measured with a differential photodiode (PD) onto which the image of the cuticular plate from the microscope was projected. Placement of the PD was accomplished remotely by a computer-controlled micromanipulator, so as not to perturb whole-cell recording. The PD was backlit by two fiber optic beams projected through the microscope's camera port onto a $30 \%$ mirrored glass coverslip base of the perfusion chamber, and reflected back to a CCD video camera via a $90^{\circ}$ prism to allow $P D$ placement during simultaneous cell visualization on a mixed video-computer monitor (Matrox Corp., Dorval, Quebec, Canada). Backlighting was not required after calibration of the PD's position on the monitor. The frequency response of the PD system was measured by driving an onbiased light-emitting diode (LED) and had a $3 \mathrm{~dB}$ rolloff at $6 \mathrm{kHz}$ (Fig. 1). The validity of the PD system was verified by measuring the movements of a glass probe driven by a piezoelectric bimorph (Fig. 1, insets). Sinusoidal voltage bursts (onset and offset linearly ramped) of frequencies ranging from 11.7 to $3201 \mathrm{~Hz}$ were delivered to OHCs under voltage clamp. PD output and whole-cell currents were filtered at $10 \mathrm{kHz}(12$ $\mathrm{dB} /$ octave) and collected simultaneously using a sampling rate of 20 $\mathrm{kHz}$ for AC analysis or up to $50 \mathrm{kHz}$ for step analysis. Responses were averaged 200 times. Fundamental magnitude and phase of the mechanical responses were measured by fast Fourier transformation (FFT) of the central portion of the digitized waveforms using the software package MATLAB. Mechanical responses were corrected for the phase and magnitude characteristics of the PD system. Absolute calibration of cell movements was determined by measuring off the video monitor the cell movement in response to a large steady state depolarizing voltage stimulus (Santos-Sacchi, 1989).

Motility estimates using a photodiode technique rely upon intensity measures of the projected image of the OHC's cuticular plate. The problems with such a technique have been addressed by Clark et al. (1990). In the present study, care was taken to maintain the position of the cells within the bounds of the differential photodiode; in order to check this, cells were visualized on a video monitor during data collection. While magnitude measures may be affected by changes in image intensity, phase measures should not. Similar cutoff frequencies of the mechanical responses were obtained from phase and magnitude data, indicating that the image intensity did not change during the data collection period, typically about 5 min.

The mechanical response $\Delta L(v)$ was fit with a Boltzmann function:

$$
\Delta L(v)=\left[\frac{\Delta L_{\max }}{1+e\left(V_{m}-V_{h}\right) / b}\right]+\Delta L_{\min },
$$

where $\Delta L_{\max }$ and $\Delta L_{\min }$ are the fitted maximum and minimum length changes from the resting state, $b$ is the voltage slope factor, and $V_{h}$ is the voltage at half-maximal length change.

\section{Results}

The OHC changes length when its transmembrane potential is altered. Figure $2 A$ demonstrates the $\mathrm{V}$-M function for an isolated $\mathrm{OHC}$ using step voltage commands from a holding potential of $-68.4 \mathrm{mV}$. The function follows a saturating Boltzmann relation, such that the mechanical response is larger in the depolarizing (shortening) direction near the cell's normal resting potential. This is a consequence of the holding potential being displaced from $V_{h}$. For this cell, a maximum slope of about 21 $\mathrm{nm} / \mathrm{mV}$ at $-26 \mathrm{mV}$ is calculated (Fig. $2 B$ ). Responses as large as $30 \mathrm{~nm} / \mathrm{mV}$ have been observed (Santos-Sacchi and Dilger, 1988).

The OHC membrane possesses a nonlinear charge movement that is correlated in time and voltage dependence with induced length changes (Ashmore, 1989; Santos-Sacchi, 1990, 1991b); this nonlinear charge probably represents the movement of membrane-bound voltage sensors responsible for the cell's voltage-dependent mechanical response. Figure 3 demonstrates that the kinetics of the charge movement are such that the time 


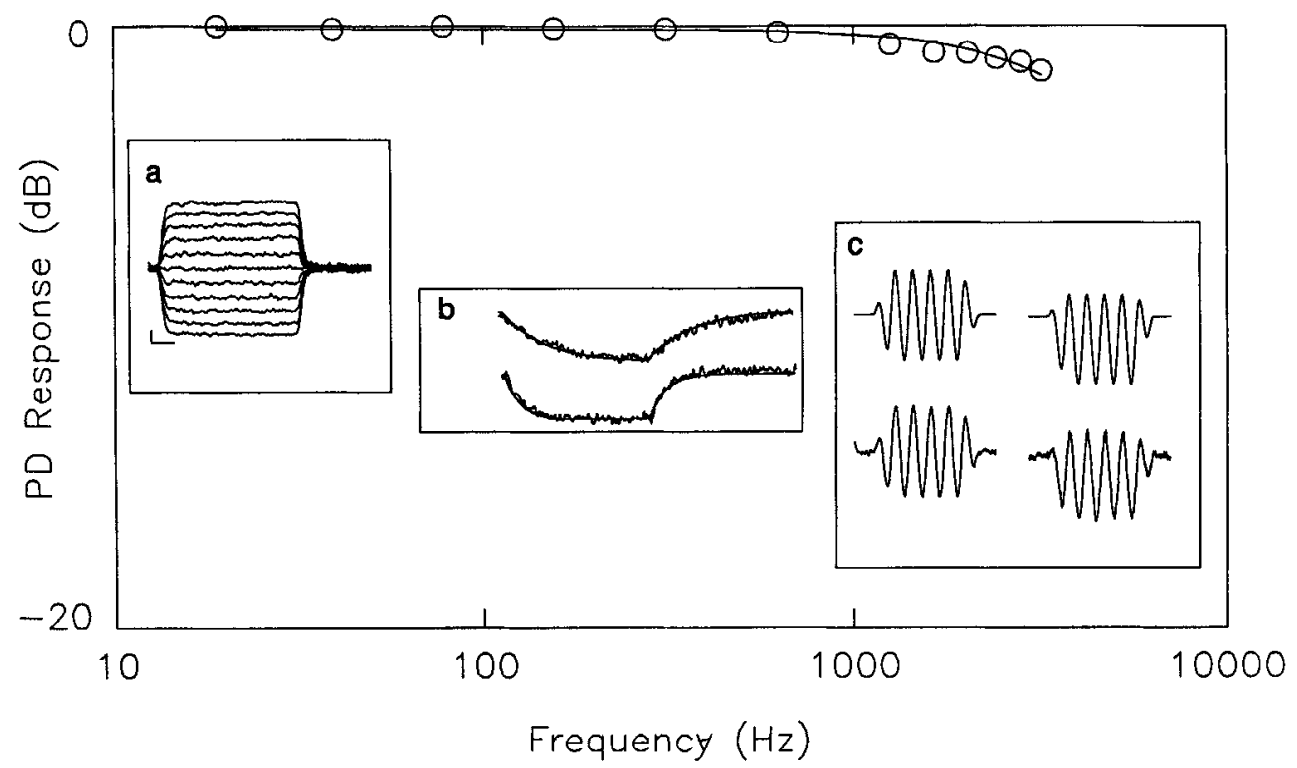

Figure 1. Characteristics of the movement measurement system. Frequency response of differential PD output (open circles, averaged 200 $\times$ ) in response to off-centered LED emission elicited by sine wave bursts. Cutoff frequency was $6 \mathrm{kHz}$. Insets, Outputs from PD in response to simulated cell movement. The tip of a glass microelectrode shank was melted to a sphere of about $15 \mu \mathrm{m}$; transmitted light produced a bright area in the sphere's center, which was used to mimic the bright $\mathrm{OHC}$ cuticular plate observed under Hoffmann optics. The artificial cell was attached to a piezoelectric bimorph and moved using various voltage waveform inputs to test the linearity and frequency following capability of the PD measurement system. $a$, PD output measured in response to bimorph movements produced by fixed incremental voltage steps (filtered to avoid bimorph resonance at $2 \mathrm{kHz}$ ). Linearity is good. Response filtered at $800 \mathrm{~Hz}$. Calibration vertical, $0.1 \mu \mathrm{m} ;$ horizontal, $2 \mathrm{msec}$. $b$, PD output (noisy traces) in response to bimorph voltage stepped through a filter of $100 \mathrm{~Hz}$ (top trace) and $300 \mathrm{~Hz}$ (bottom trace). Simultaneously recorded voltage (solid traces) corresponds faithfully to the PD output. Maximum excursion is about $1 \mu \mathrm{m}$. Pulse width is 5 msec. $c$, Bimorph was stimulated with sinusoidal voltage bursts $(156 \mathrm{~Hz}$ ). Two traces on top are measured voltage; corresponding two traces on bottom are PD output (filtered at $800 \mathrm{~Hz}$ ). Excellent frequency following is apparent. Stimulus and response traces on right demonstrate that the measurement system is capable of detecting DC offsets.

constant of the voltage-clamp amplifier limits their study under whole-cell configuration. That is, the time constant of nonlinear capacitive current decay follows changes in the time constant of the clamp amplifier, indicating that the kinetics are faster than the fastest clamp speed presently attainable. Measures of $\mathrm{OHC}$ mechanical response induced by voltage steps indicate a similar trend (Fig. $4 A$ ). In this case, an $\mathrm{OHC}$ was stepped from a holding potential near $-70 \mathrm{mV}$ to about $40 \mathrm{mV}$, while the clamp time constant was modified between 0.8 and $0.52 \mathrm{msec}$ with series resistance feedback compensation. Both movement onset and offset are directly correlated with clamp time constant. Note that fitted single exponentials of the movement onset appear faster than the clamp time constant. This is due to the fact that the voltage steps are saturating, and is consistent with model simulations based on the OHC's V-M function (see Discussion). It was noted by Ashmore (1987) that delays in mechanical response onset occurred following voltage step onset. The insets in Figure $4 A$ illustrate that clamp time constant modifications do not appear to influence the mechanical response onset, which occurred within $40 \mu \mathrm{sec}$ of stimulus onset in this case. In other cells, however, delays were observed up to about $100 \mu \mathrm{sec}$ (Fig. $4 B$ ). It is conceivable that alterations of cell turgor that occur during whole-cell voltage clamp may underlie this delay phenomenon (Santos-Sacchi, $1991 \mathrm{~b}$ ). Figure $4 C$ illustrates the mechanical response of an OHC driven by a voltage step depolarization of about $5 \mathrm{msec}$ in duration, with one of the fastest clamp time constants attained, $0.14 \mathrm{msec}$. The onset of the mcchanical response is rapid (onset $r$ of a double exponential fit, $0.240 \mathrm{msec}$ ); a maximum velocity of $6.5 \mathrm{~mm} / \mathrm{sec}$ is calcu- lated, which is about 3.5 times faster than previous estimates of OHC velocity (Ashmore, 1987).

The form of the V-M function (Fig. $2 A$ ) indicates that the mechanical response will include both $\mathrm{AC}$ and $\mathrm{DC}$ components when a sinusoidal voltage command is delivered about the holding potential. Such mechanical rectification has been demonstrated with low-frequency sinusoidal stimuli (Evans et al., 1989; Santos-Sacchi, 1989). Figure 5 illustrates this phenomenon as a function of stimulus frequency. Sinusoidal voltage command stimuli of frequencies ranging from 11.7 to $3201 \mathrm{~Hz}$ elicit $\mathrm{AC}$ and DC mechanical responses. Figure $5 A$ documents the rectificd naturc of the V-M function of this cell based on the response from an $11.7 \mathrm{~Hz}$ transmembrane voltage stimulus. $\mathrm{Me}$ chanical rectification is also apparent at higher stimulus frequencies, as reflected in the DC mechanical components present in the raw data (Fig. $5 B$ ). The measured reduction in magnitude of the mechanical response as frequency increases is not inherent in the $\mathrm{OHC}$, but is due to limitations of the voltageclamp amplifier. That is, command voltage magnitude decreases with increasing frequency because of the voltage clamp's limited frequency response; ${ }^{-1}$ therefore, voltage dependent $\mathrm{AC}$ mechanical responses roll off as well (see below).

As command voltage magnitude decreases (due to the clamp time constant), there is a disproportionate decrease in the mag-

\footnotetext{
${ }^{1}$ The effectiveness of the whole-cell voltage clamp technique is limited by the patch electrode's series resistance and the cell's impedance. The speed at which a voltage can be imposed across the membrane of a cell depends upon the clamp time constant ( $\tau=R_{s} \| R_{m} C_{m}$ ). This time constant corresponds to the effective bandwidth of AC stimulation $\left(f_{\text {cutoff }}=1 / 2 \pi \tau\right)$.
} 
A

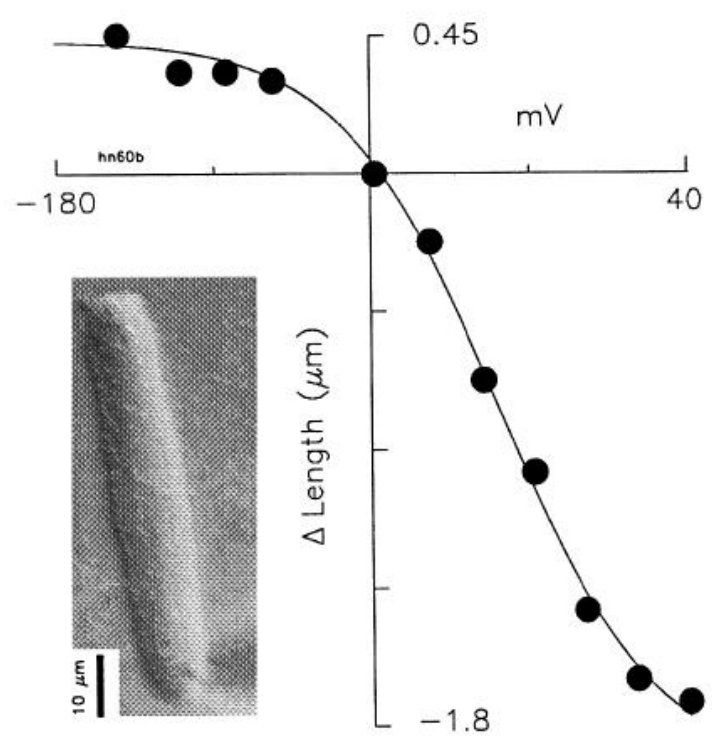

B

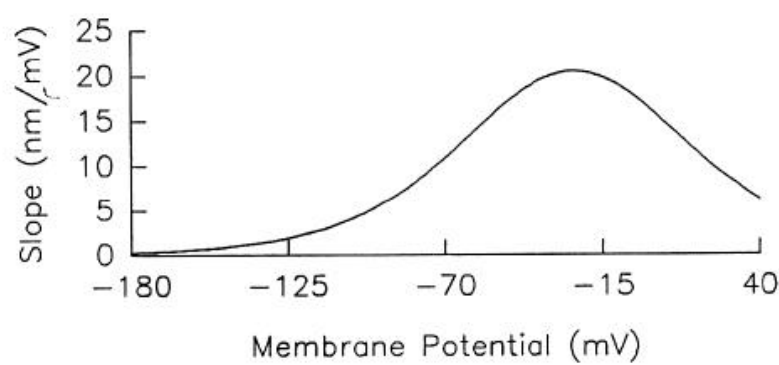

Figure 2. A, Change in length of an isolated $\mathrm{OHC}$ in response to voltage steps delivered from a holding potential of $-68.4 \mathrm{mV}$. The residual series resistance has been corrected. Hyperpolarizing steps from the holding potential induce elongations whose magnitudes saturate more rapidly with step potential than do contractions due to depolarizing steps. The mechanical response $\Delta L(v)$ was fit with a Boltzmann function (Eq. 1; solid line). The least squares fit gives $V_{h}=-25.7 \mathrm{mV}$ and $b=$ $27 \mathrm{mV}$. Normal extracellular solution, and $\mathrm{KCl}$-containing patch pipette. Cell length measures were made off the video monitor. Inset, Digitally captured video image of the whole-cell voltage-clamped OHC. $B$, Slope of the Boltzmann fit above, indicating the voltage sensitivity of the mechanical response across voltage. The sensitivity at the holding potential of $-68.4 \mathrm{mV}$ is smaller than the maximum.

nitude of the DC mechanical component relative to the decrease of the AC mechanical component. This phenomenon is an inherent property of the V-M function of the $\mathrm{OHC}$; as the AC voltage excursion about the holding potential is reduced, the input-output function within the limited stimulus region approaches linearity. Although Evans et al. (1990) obtain similar V-M functions (see Fig. $5 A$, solid triangles), they report a linear correspondence between AC and DC mechanical responses as voltage magnitude is altered. However, Figure $5 C$ exemplifies the nonlinear correspondence inherent in the V-M function by plotting the ratio of $\mathrm{DC}$ to $\mathrm{AC}$ mechanical response as a function of AC voltage magnitude. The measured ratio (open circles) decreases as the stimulating voltage magnitude decreases, and is well predicted (solid line) from the V-M function of this cell (Fig. 5A). This observation indicates that the form of the V-M function measured at $11.7 \mathrm{~Hz}$ is preserved at higher frequencies; that is, the nature of the function is frequency independent.

The top panels of Figure $6, A$ and $B$, examine the magnitude of the mechanical response fundamental (obtained by FFT) and

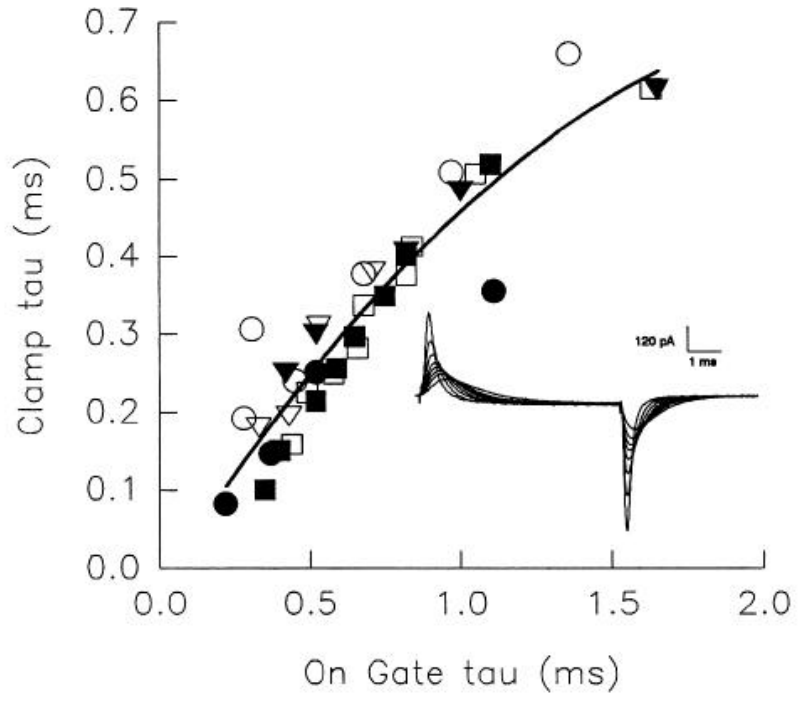

Figure 3. Dependence of on-gate current time constant upon time constant of clamp amplifier. Six cells (different symbols) were held at a potential of $-80 \mathrm{mV}$ and alternately pulsed to $40 \mathrm{mV}$ above and below the holding potential. Nonlinear capacitive currents were unmasked by averaging the resultant currents 200 times ( $\pm P$ technique; Armstrong and Bezanilla, 1973). Clamp time contants were determined by fitting single exponentials to the decaying current transient in response to a $-10 \mathrm{mV}$ step. Time constants of on-gate currents were also single exponential fits of current decay. Clamp time constant was modified by adjusting the electronic compensation for the series resistance. Reduction of clamp time constant caused reduction of gate time constant. Inset, A series of nonlinear capacitive current traces from a single $\mathrm{OHC}$ under different clamp time constant conditions. Note the shift in the speed of current response. Both on-gate and off-gate time constants are directly influenced by clamp time constant. $\mathrm{CsCl}$ electrode solution. Extracellular solution was Leibovitz with $10 \mathrm{~mm}$ tetraethylammonium (TEA) and $300 \mathrm{~nm}$ TTX.

compare it to the voltage delivered to the cell as predicted from the clamp time constant, before (top panel, Fig. $6 A$ ) and after (top panel, Fig. $6 B$ ) series resistance compensation. The cutoff frequency of the cell's mechanical response increased following compensation of the series resistance. The mechanical response rolloff roughly follows the rolloff of the transmembrane voltage, demonstrating that the mechanical response can follow rapid voltage fluctuations quite faithfully $\left(f_{\text {cutoff }} \sim 1 \mathrm{kHz}\right)$. This is inmarked contrast to the limited frequency response $\left(f_{\text {cutoff }} \sim 60\right.$ $\mathrm{Hz}$ ) reported by Ashmore (1987; see thick line in top panels of Fig. $6 A, B)$. The analysis of phase data presents a more robust test of the voltage dependence hypothesis. In an RC-dominated system, such as the OHC under voltage clamp, as voltage command frequency is increased, an asymptotic phase separation of 1.57 radians $\left(90^{\circ}\right)$ will develop between injected current and voltage. Voltage phase will lag that of current. The clamp time constant, $R_{s} \| R_{m} C_{m}$, dictates the resultant frequency dependence of the separation. The bottom panels in Figure 6, indeed, demonstrate that the mechanical response follows the phase of the induced transmembrane voltage and not that of the transmembrane current. Similar data on the magnitude and phase of current, voltage, and motility obtained from four additional cells, each with a different clamp time constant, are presented in Figure 7. In all, an asymptotic phase separation between motility and injected transmembrane current is reached [1.66 \pm 0.18 radians at $625 \mathrm{~Hz}$ (mean $\pm \mathrm{SD} ; n=6$ cells)], as would be 
A

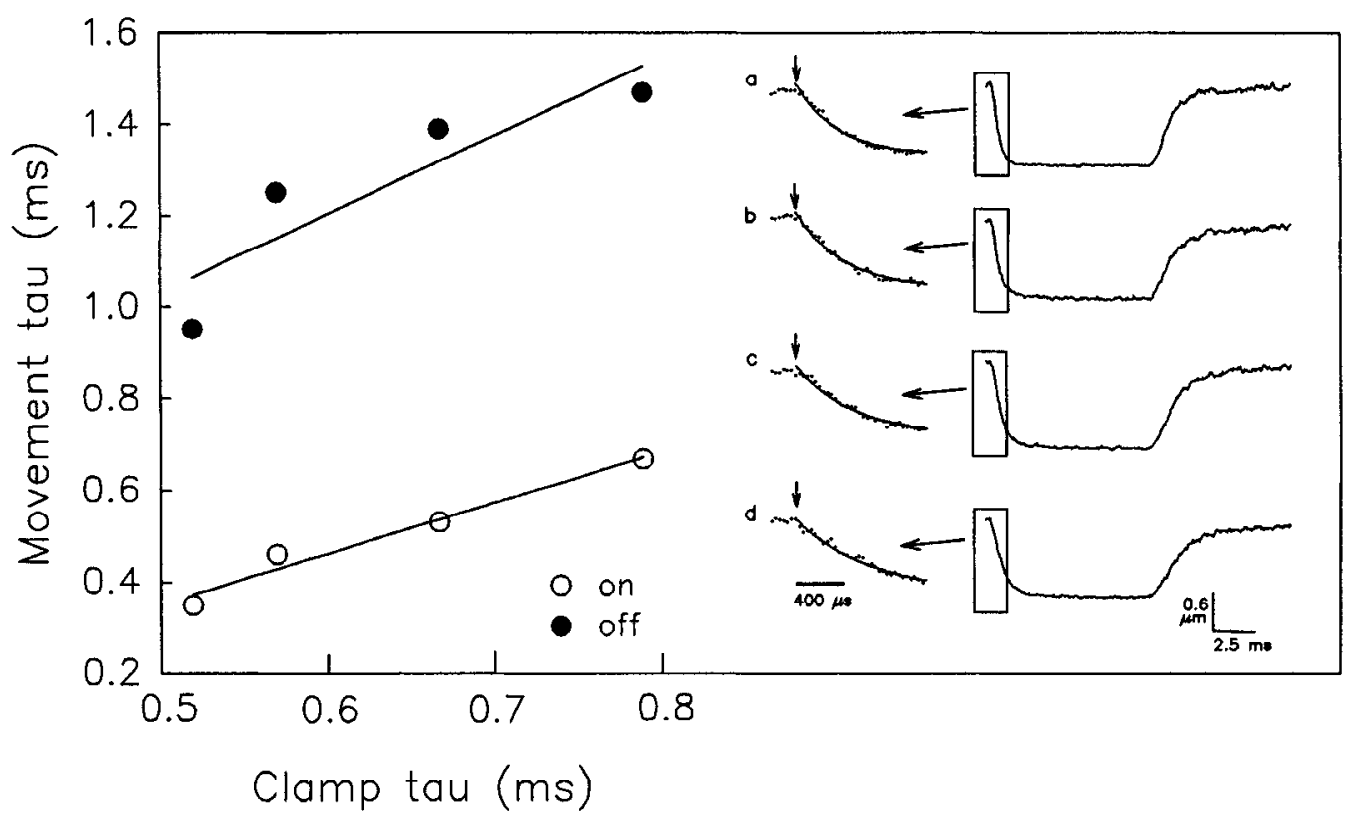

B

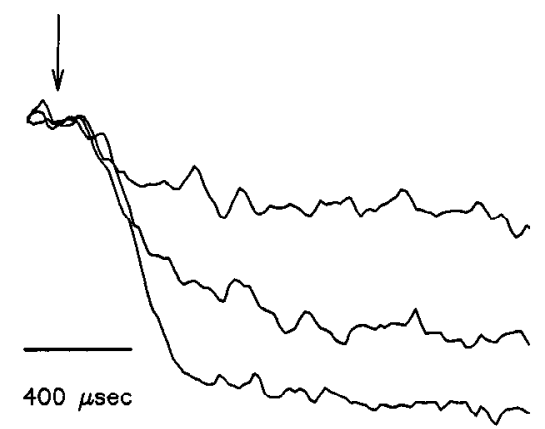

C

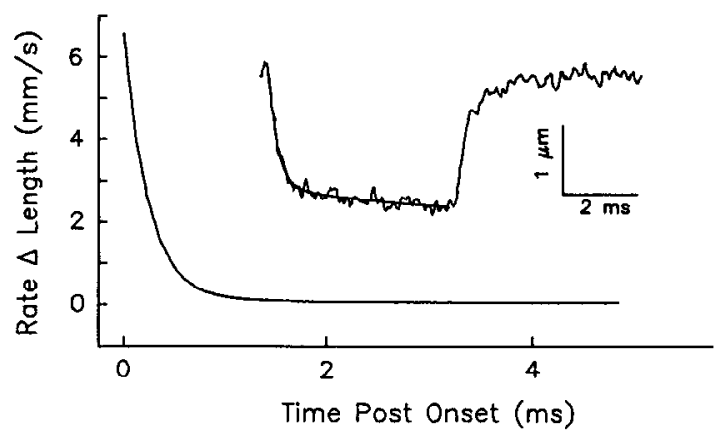

Figure 4. A, Effect of clamp time constant upon speed of OHC movement induced by voltage steps. An OHC was nominally held at $-80 \mathrm{mV}$ and stepped to $+40 \mathrm{mV}$ for 10 msec. Traces $a-d$ represent the contraction of the OHC (photodiode output) as the clamp time constant is modified. Responses were averaged $200 \times$. Single exponentials were fit to the onset (expanded fits shown) and offset of cell movement. It is clear that movement time constants are dependent upon clamp time constants. Downward arrows of expanded onset traces indicate voltage step onset. Holding potential and steady state step potential (corrected for series resistance) were $a,-73.5 \mathrm{mV}, 36.8 \mathrm{mV} ; b,-72.8 \mathrm{mV}, 36.6 \mathrm{mV} ; c,-71.1 \mathrm{mV}, 35.8 \mathrm{mV} ; d$, $-69.2 \mathrm{mV}, 35 \mathrm{mV}$. $B$, Traces represent mechanical responses of an OHC stepped nominally to $-30,0$, and $+30 \mathrm{mV}$ from a holding potential of $-80 \mathrm{mV}$. Downward arrow indicates voltage step onset. Note the delay in onset of the mechanical responses. Also note the saturation of the response at the most depolarized potential, and the resultant apparent decrease in the onset time constant compared to the other responses. $C$, Rate of length change of an $\mathrm{OHC}$ to a depolarizing step from $-78 \mathrm{mV}$ to $+29 \mathrm{mV}$ (residual scries resistance corrccted). Ratc was obtained from the first derivative of the fitted mechanical response to inset. Inset, Mechanical response filtered at $3.184 \mathrm{kHz}$ and fit with a double exponential (smooth line). The time constants were $0.24 \mathrm{msec}$ and $5 \mathrm{msec}$, with an amplitude ratio of 4:1. Clamp time constant was $0.14 \mathrm{msec}$.

expected for a voltage driven process. This is strong evidence favoring the voltage dependence hypothesis of OHC motility. ${ }^{2}$

The relationship of the mcchanical response time constant (i.e., cutoff frequency) to that of the voltage clamp is summarized for five cells in Figure 8. The frequency response of $\mathrm{OHC}$ motility is positively correlated with the speed of the voltage clamp.

\footnotetext{
${ }^{2}$ It should be noted that the measured current phase consists of both a resistive and capacitive component, and that at high frequencies the capacitive component dominates. However, the current through membrane-resistive elements is always in phase with transmembrane voltage. Nevertheless, alterations of the resistive currents by means of various ionic blocking agents do not interfere with voltageinduced mechanical responses (Santos-Sacchi and Dilger, 1988; Santos-Sacchi, 1989, 1991b).
}

For two OHCs (circles and diamonds), mechanical responses were obtained before and after series resistance compensation; mechanical response cutoff frequency parallcled the resulting changes in clamp speed. There is, however, a trend for the mechanical response fundamental to roll off at lower frequencies than the applied transmembrane voltage. This phenomenon may be a consequence of the nonlinear V-M function, as a similar trend is also found with model simulations (solid line, Fig. 8).

\section{Discussion}

The data presented here provide insight into the mechanism and potential significance of $\mathrm{OHC}$ motility. The observation 
A

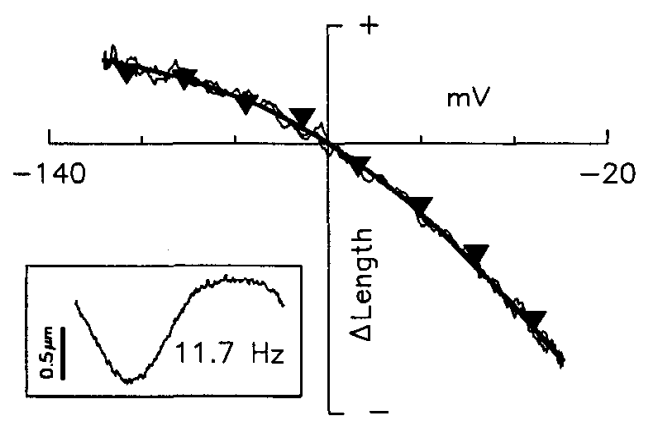

C

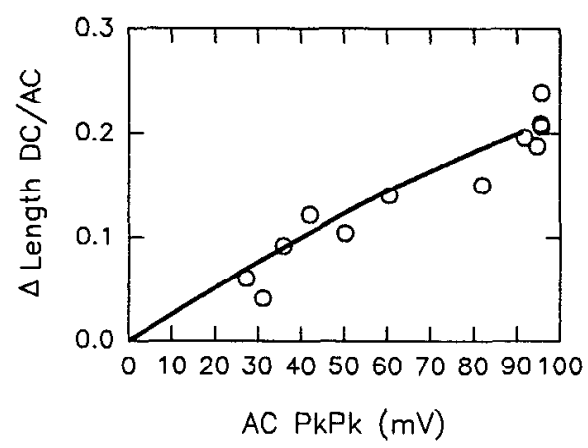

B

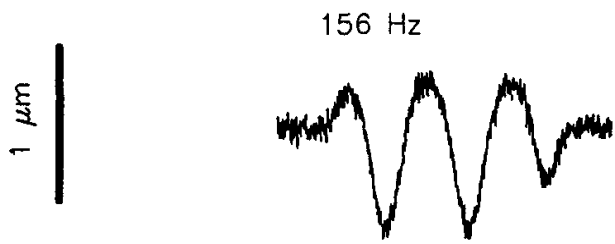

$78 \mathrm{~Hz}$

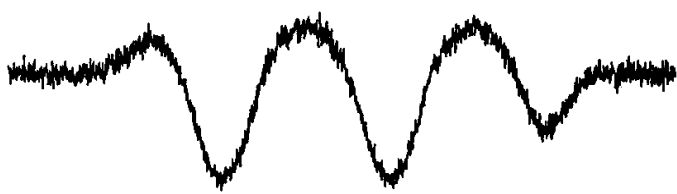

$39 \mathrm{~Hz}$

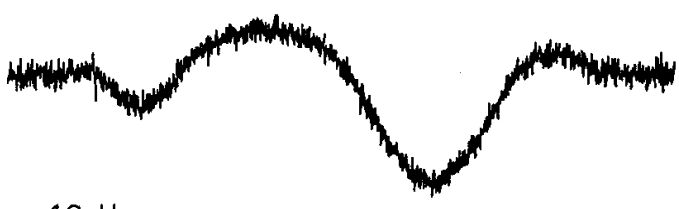

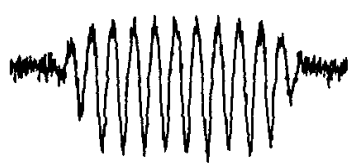

$312 \mathrm{~Hz}$

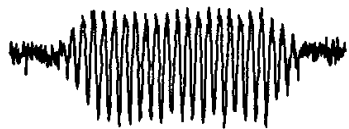

$625 \mathrm{~Hz}$

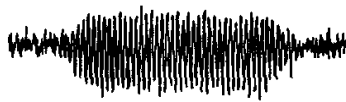

$1250 \mathrm{~Hz}$

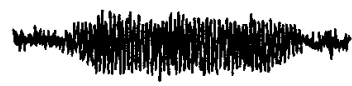

$1640 \mathrm{~Hz}$

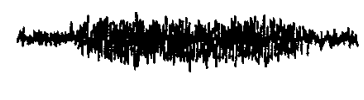

$2031 \mathrm{~Hz}$

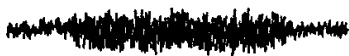

$2421 \mathrm{~Hz}$

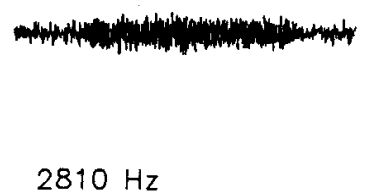

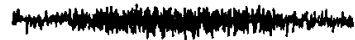

$3201 \mathrm{~Hz}$

Figure 5. OHC AC and DC mechanical responses elicited by AC voltage stimulation. $A$, Voltage versus movement for an $11.7 \mathrm{~Hz}$ voltage stimulus. Voltage is the estimated intracellular potential obtained from the command potential corrected for series resistance and phase shifted to minimize phase differences between it and movement response. The solid line is a fit to a portion of a Boltzmann function with $V_{h}=-30.5 \mathrm{mV}$ and $b=31$ $\mathrm{mV}$. For comparison, the data (solid triangles) of Evans et al. (1990) based on step commands about the authors' estimated resting potential of $-60 \mathrm{mV}$ were scaled and superimposed (see Results and Discussion). Inset, Movement response waveform smonthed with five point running average. Peak-to-peak (PkPk) response is about $1 \mu \mathrm{m}$. B, Photodiode output indicating the movement of the OHC in response to voltage sine wave bursts of varying frequency. The movement consists of an $\mathrm{AC}$ and $\mathrm{DC}$ response, both of which decrease as a function of frequency; this results from the decrease of the magnitude of voltage stimulation duc to the voltagc-clamp time constant. DC responses can be observed above $3 \mathrm{kHz}$ but decrease in magnitude disproportionately compared to $\mathrm{AC}$ response magnitude. $C$, Ratio of DC movement to $\mathrm{AC} P \mathrm{Pk}$ movement versus PkPk voltage stimulus corrected for the frequency-dependent attenuating effects of series resistance. Measures are from the raw data shown in $B$. Data were obtained by visually determining PkPk movement response and DC movement response (difference between baseline and half-PkPk response). The solid line is the predicted ratio based upon the movement versus voltage response for $11.7 \mathrm{~Hz}$ as in $A$. Note the greater susceptibility of the DC response to reduction of driving voltage magnitude. That is, the DC:AC ratio is not constant as a function of driving voltage magnitude. 
A
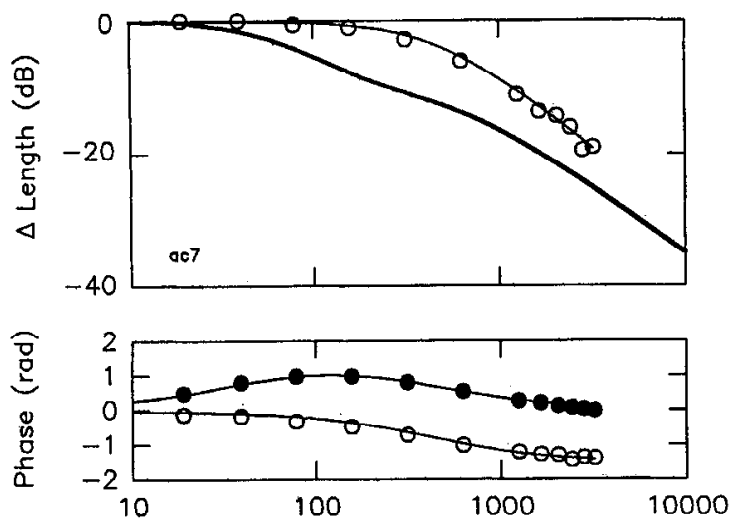

B
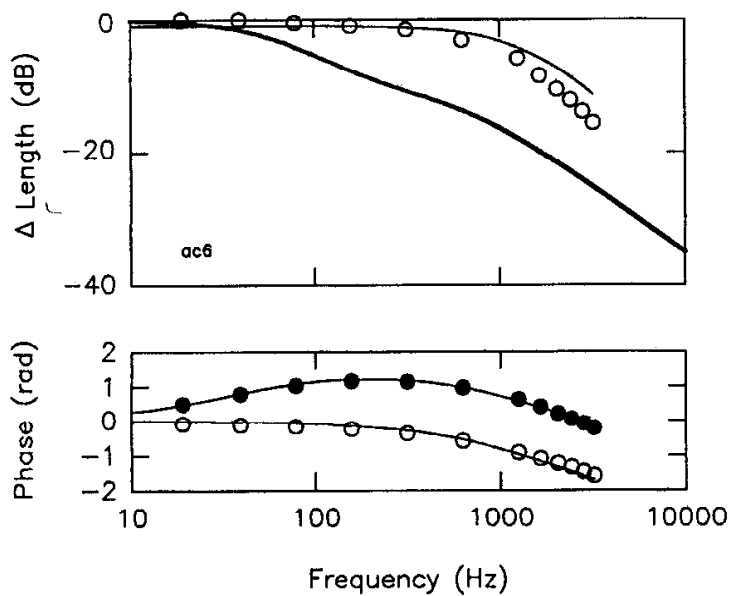

Figure 6. Frequency response (magnitude and phase) of $\mathrm{OHC}$ motility for the cell of Figure 5 with a clamp time constant of $0.38 \mathrm{msec}(A$; no series resistance compensation) or $0.125 \mathrm{msec}(B$; series resistance maximally compensated). Nominal peak voltage was $50 \mathrm{mV}$. CsCl electrode. Extracellular medium was Ca-free Leibovitz with $20 \mathrm{mM}$ TEA and 20 mu CsCl. A: Top, Magnitude. Open circles represent the fundamental magnitude of length change obtained by FFT (see Materials and Methods). The line through the data points is the predicted cell voltage using a voltage clamp-cell model (see Materials and Methods), with the electrical characteristics of the clamp-cell setup determined from the current response to a $5 \mathrm{mV}$ step $\left(R_{m}=139.5 \mathrm{M} \Omega ; C_{m}=33.3 \mathrm{pF}\right.$; clamp $\tau=$ $0.38 \mathrm{msec}$ ). For comparison, the thick line is Ashmore's fit to his data (1987, Fig. 7). Bottom, Phase. The solid circles represent the phase of the fundamental component of the simultaneously recorded current, after equipment phase correction. The open circles represent the phase of the length change fundamental. The solid lines are the predicted phase for the current and voltage using the voltage clamp-cell model component values. No absolute phase delay is included in the phase predictions. $B$, As in $A$, except clamp-cell electrical characteristics at this time were $R_{m}=125.5 \mathrm{M} \Omega, C_{m}=35.4 \mathrm{pF}$, and clamp $\tau=0.125 \mathrm{msec}$. An absolute phase delay of $25 \mu \mathrm{sec}$ is included in current and voltage predictions.

that OHC motility does indeed follow the time course and phase of transmembrane voltage stimuli provides the strongest evidence thus far that the motility mechanism is voltage dependent. $^{3}$ The presence of voltage-dependent nonlinear charge

\footnotetext{
${ }^{3}$ While the results of Dallos et al. (1991a) clearly demonstrate the elemental nature of the OHC motor, their data do not unequivocally support the voltage dependency hypothesis. Neither transmembrane current nor transmembrane voltage could be measured with the microchamber technique, and either would have been in phase opposition at the opposite poles of the cell, just as the mechanical responses were.
}

movement within the membrane of the $\mathrm{OHC}$ (indicative of membrane-bound voltage sensors) corroborates this concept (Ashmore, 1989; Santos-Sacchi, 1990, 1991b). Similarities between characteristics of the nonlinear charge movement and motility, including voltage dependence $\left(V_{h}, b\right)$, susceptibility to charge screcning, and reversible block by gadolinium ions, indicate that the estimated 4000 voltage sensors $/ \mu \mathrm{m}^{2}$ control OHC length through an equal number of associated elemental motors (Santos-Sacchi, 1991b). Assuming that the motors are equally distributed within the membrane along the extent of the subsurface cisternae, it is calculated that each elemental motor would contribute an effective unit displacement of about $1 \mathrm{~nm}$ in the longitudinal direction. The actual displacement vector may not be purely longitudinal (Dallos et al., 1991b). Ultimately, the dependence of $\mathrm{OHC}$ motility on transmembrane voltage and the form of the V-M function will determine the physiological significance of $\mathrm{OHC}$ motility.

\section{Velocity and frequency response of $\mathrm{OHC}$ motility}

An important indicator for evaluating the significance of $\mathrm{OHC}$ motility in inner ear function is its frequency response. Certainly, there will be a point at which the $\mathrm{OHC}$ will be unable physically to follow an imposed transmembrane AC voltage, and a determination of this cutoff frequency will permit a more realistic assessment of the OHC's mechanical influence in the high-frequency region of the cochlea. Unfortunately, the maximum velocity and the frequency extent of $\mathrm{OHC}$ motility are as yet undetermined, due to the speed limitations imposed by the voltage-clamp amplifier. Thus, the current maximum $\mathrm{OHC}$ velocity measured during a step response $(6.5 \mathrm{~mm} / \mathrm{sec}$; Fig. $4 \mathrm{C})$, or estimated from the AC data [Fig. $6 B ;(\Delta \mathrm{L} \omega) 4 \mathrm{~mm} / \mathrm{sec}$ at $1250 \mathrm{~Hz}$ ] is likely to be an underestimate. Indeed, the $\mathrm{OHC}$ mechanical response probably extends beyond the widest frequency response measured, which approached a $1 \mathrm{kHz}$ cutoff.

It is interesting to note that although the speed of the mechanical response follows changes in the speed of the imposed voltage, the time constants of each are not necessarily equal. In fact, in Figure 4 it was illustrated that the mechanical on-response can have an apparent time constant faster than that of the imposed voltage; contrarily, the off-response can be slower than the imposed voltage. This is not unusual for a nonlinear system, and the same effects are simulated for a model V-M function in Figure 9. It is clear that despite a constant membrane potential time course, level-dependent changes in the apparent time constant of the mechanical responsc arisc. Mechanical response saturation at the extremes of the V-M function accounts for much of these effects. The tendency for the mechanical frequency response to roll off sooner than the imposed voltage frequency response (Fig. 8) may also reflect the effects of the nonlinear V-M function. If the resting potential (holding potential) were equal to $V_{h}$ and the stimulus amplitude were very small, the time course of the mechanical response would more closely mirror that of the driving voltage.

Despite their limitations, the measurements of velocity and frequency response reported here more closely reflect $\mathrm{OHC}$ mechanical response capabilities than previous measures (Ashmore, 1987), and are useful in evaluating some timely issues. For example, electrically evoked otoacoustic emissions recorded from the ear canal, presumably due to the activity of OHCs, have been measured in pass bands up to several $\mathrm{kHz}$ (Hubbard and Mountain, 1990). These investigators have suggested, based on Ashmore's (1987) mechanical frequency response data, that 
A
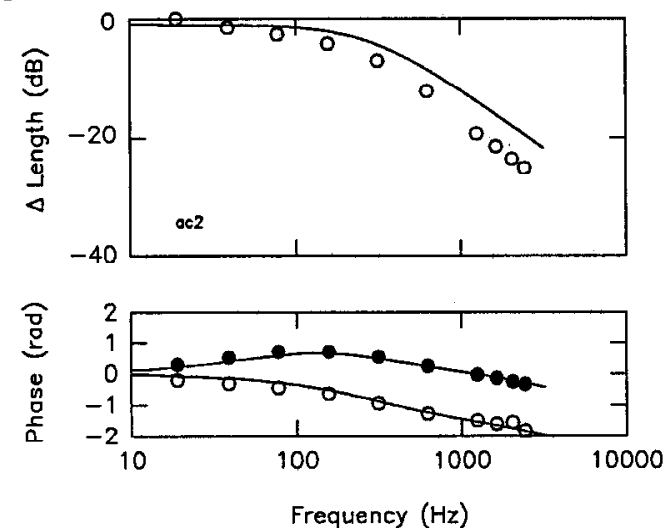

C
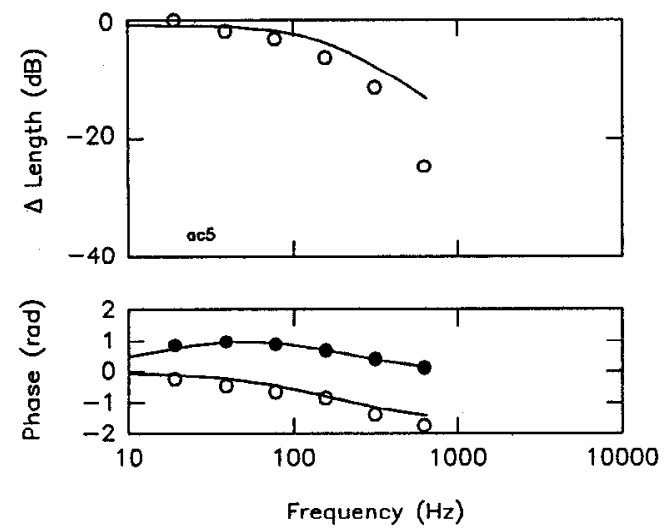

B
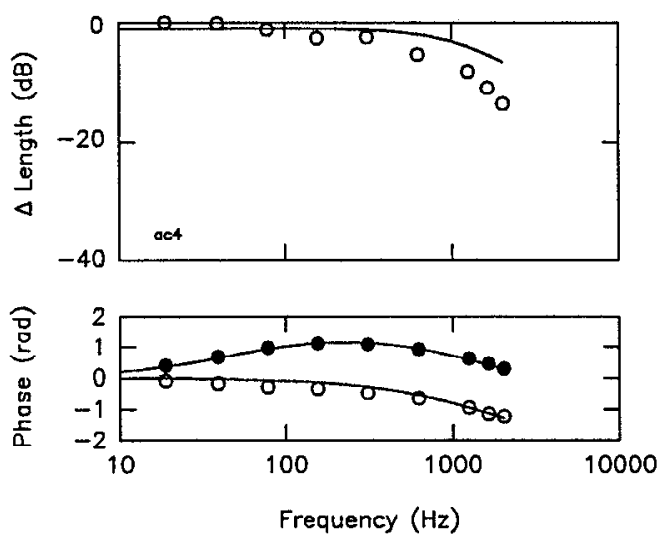

D
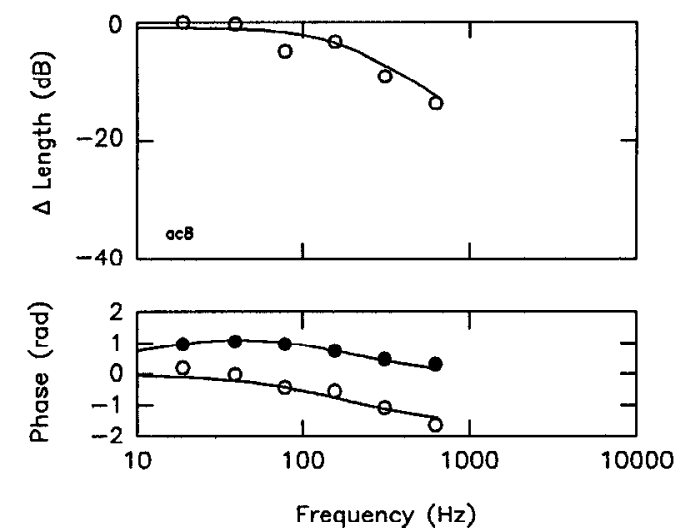

Figure 7. Frequency response for four additional cells (magnitude and phase) with varying clamp time constants. See Figure 6 for details. Clampcell electrical characteristics are as follows: $A, R_{m}=96 \mathrm{M} \Omega, C_{m}=24.73 \mathrm{pF}$, clamp $\tau=0.553$ msec. Absolute phase delay, $25 \mu \mathrm{sec}$. Nominal peak voltage was $60 \mathrm{mV}$. CsCl electrode. Extracellular medium was Leibovitz with $20 \mathrm{~mm}$ TEA. $B, R_{m}=79 \mathrm{M} \Omega, C_{m}=41.89 \mathrm{pF}$, clamp $\tau=0.128 \mathrm{msec}$. Absolute delay, $20 \mu \mathrm{sec}$. Nominal peak voltage was $40 \mathrm{mV}$. CsCl electrode. Extracellular medium was Leibovitz with $20 \mathrm{~mm}$ TEA, $300 \mathrm{nM}$ TTX, and $1 \mathrm{mM} \mathrm{CdCl} . C, R_{m}=346 \mathrm{M} \Omega, C_{m}=27.35 \mathrm{pF}$, clamp $\tau=1.00 \mathrm{msec}$. Absolute delay, $20 \mu$ sec. Nominal peak voltage was $40 \mathrm{mV}$. CsCl electrode. Extracellular medium was Leibovitz with $20 \mathrm{mM}$ TEA and $300 \mathrm{nM}$ TTX. $D, R_{m}=490 \mathrm{M} \Omega, C_{m}=33.0 \mathrm{pF}$, clamp $\tau=0.934 \mathrm{msec}$. Absolute delay, $20 \mu \mathrm{sec}$. Nominal peak voltage was $100 \mathrm{mV}$. CsCl electrode. Extracellular medium was Leibovitz with $10 \mathrm{~mm}$ TEA and $300 \mathrm{nM}$ TTX.

the $\mathrm{OHC}$ length changes are too low pass to account for such high-frequency phenomena. Clearly, the data presented here suggest that $\mathrm{OHC}$ length changes may be significant at those acoustic frequencies where electrically evoked otoacoustic emissions occur. Ashmore's (1987) observation that OHC motility was extremely low pass was probably due to the very slow clamp time constants achieved in that study (see footnote 3 of SantosSacchi, 1989).

Since the in vivo receptor potential will provide the $\mathrm{OHC}$ motility driving force, the effectiveness of evoked AC mechanical events in influencing organ of Corti micromechanics at high frequencies can be evaluated to a first approximation by an assessment of $\mathrm{OHC}$ receptor potential characteristics. Thus, it is known that $\mathrm{OHC} \mathrm{AC}$ receptor potentials for cells with high characteristic frequencies $(>15 \mathrm{kHz})$ are quite small due to the cell's RC time constant $\left(f_{\text {cutoff }} \sim 1.2 \mathrm{kHz}\right)$; AC potentials of about $15 \mu \mathrm{V}$ have been recorded in these cells near auditory threshold (Russell et al., 1986). Consequently, it has been argued that evoked $\mathrm{AC}$ movements of an $\mathrm{OHC}$ with a resting potential of $-70 \mathrm{mV}$ are much smaller $(\sim 20 \mathrm{~dB})$ than basilar membrane movements near auditory threshold (Santos-Sacchi, 1989; but see Santos-Sacchi, 1991b).
The present velocity estimates, though clamp limited, appear incompatible with the electro-osmotic theory of $\mathrm{OHC}$ motility proposed by Brownell and Kachar (1986). The rate of movement is far greater than that attributable to an electro-osmotic mechanism; experiments on a variety of preparations indicate the maximum velocity achievable is $1 \mu \mathrm{m} / \mathrm{sec}$ per $\mathrm{V} / \mathrm{cm}$ (McLaughlin and Mathias, 1985). The steady state voltage drop across the membrane of the OHC in Figure $4 C$ was $107 \mathrm{mV}$. The maximum field strength along a cell of $70 \mu \mathrm{m}$, assuming that the total imposed voltage drops across the length of the cell (which is unlikely, since space-clamp estimates indicate little longitudinal decay) would be $15.3 \mathrm{~V} / \mathrm{cm}$. Thus, an electro-osmotic based velocity of $15.3 \mu \mathrm{m} / \mathrm{sec}$ is predicted, over 2 orders of magnitude smaller than the observed maximum velocity. Iwasa and Kachar (1989) employed the same argument against an electro-osmotic mechanism, although the disparity between their velocity measures and electro-osmotic estimates were not as great as those reported here. Furthermore, an electro-osmotic mechanism would predict that the velocity, not the displacement, of OHC motility would be in phase with voltage. This is in conflict with the phase data reported here. It should be noted that velocities associated with electro-osmosis are derived for 


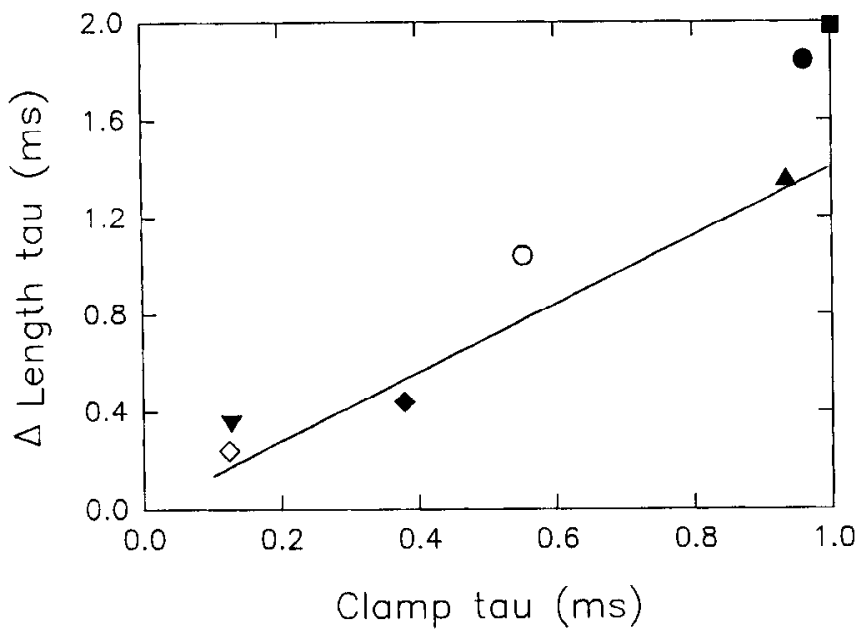

Figure 8. Clamp time constant versus measured time constant of movement. Time constants of movement were from linear interpolation of $3 \mathrm{~dB}$ breakpoint of measured magnitude response as in Figure 2. Data from a total of five cells (different symbols) are presented, with two cells (circles and diamonds) being measured at two different clamp time constants (open and solid symbols). Clamp time constant dictates frequency response of $\mathrm{OHC}$ motility. However, the mechanical response has a slower time constant (lower cutoff frequency) than the voltage command. This may be a function of the nonlincar V-M function since model simulations predict this type of behavior. For example, the solid line was obtained by performing the same type of analysis on a mode $\mathrm{V}-\mathrm{M}$ function with Boltzmann parameters of $b=26 \mathrm{mV}$ and $V_{h}^{r}=-30$ $\mathrm{mV}$, at a holding potential of $-70 \mathrm{mV}$, with a peak $\mathrm{AC}$ voltage stimulation of $50 \mathrm{mV}$.

steady state conditions, and the preceding arguments may not be absolutely appropriate. Nevertheless, in the absence of a more complete electro-osmotic model of OHC motility, it remains questionable whether electro-osmosis can account for the maximum velocity and phase of $\mathrm{OHC}$ motility presently found. Dallos ct al. (1991a) also dismissed an electro-osmotic mechanism based on other arguments.

\section{DC mechanical response}

Voltage-dependent $\mathrm{OHC}$ motility, analyzed under whole-cell voltage clamp, is well characterized by a two-state Boltzmann function, whose $V_{h}$ is offset in the depolarizing direction relative to the normal resting potential of the cell. A mechanical DC nonlinearity is not inherent in the $\mathrm{V}-\mathrm{M}$ function but is expressed only due to this voltage offset. This concept differs from the contention of Dallos et al. (1991b), who suggest, based on DC responses measured at very small stimulus levels, that the DC component is the result of an essential nonlinearity of the OHC's stochastic motor. Clearly, however, should the cell's resting potential and $V_{h}$ superimpose, then no DC mechanical component would arise.

The normal resting potential in vivo is near $-70 \mathrm{mV}$ (Dallos et al., 1982; Russell and Sellick, 1983). $V_{h}$ of the V-M function ranged from about $-40 \mathrm{mV}$ to $-20 \mathrm{mV}$, which to a large extent is dependent upon membrane surface charge and agents that affect the resultant surface potential (Santos-Sacchi, 1991b). Thus, a DC mechanical response appears ensured under normal in vivo conditions ${ }^{4}$ and is dependent on the many factors governing

\footnotetext{
${ }^{4}$ Actually, $V_{h}$ is not known for the in vivo situation. Unfortunately, the traditional in vitro whole-cell technique modifies both intra- and extracellular environments, so that biochemical conditions (e.g., membrane surface charge screening, phosphorylations, etc.) existing in vitro may not represent those in vivo. Thus,
}

$\mathrm{OHC}$ resting membrane potential and membrane surface potential. The effects of resting potential on the sum of elemental motor contributions, that is, on the observable OHC mechanical response, can be complex. For example, whereas shifts of the normal resting potential toward $V_{h}$ will reduce the DC component, the peak-to-peak component can grow. It is interesting to note that noise-induced threshold shift, which produces a depolarization of the OHC (Cody and Russell, 1985), should affect both $\mathrm{AC}$ and DC mechanical response production.

It is demonstrated here that the $\mathrm{OHC} \mathrm{DC}$ mechanical response is a frequency-independent consequence of the $\mathrm{V}-\mathrm{M}$ function. The persistence of the DC mechanical response above $3 \mathrm{kHz}$ is the first demonstration that the mechanical rectification extends to physiologically important frequencies. Previous studies have reported $\mathrm{DC}$ responses at frequencies between 10 and $200 \mathrm{~Hz}$ (Evans et al., 1989; Santos-Sacchi, 1989). It is conceivable that DC mechanical responses of OHCs could provide a bias that may change mechanical characteristics (e.g., stiffness) of the organ of Corti-basilar membrane complex, leading in some manner to enhanced tuning. At first thought, this may appear to alleviate some of the problems associated with the membrane filtering effects on the high-frequency AC mechanical response. However, the DC nonlinearity is highly stimulus level dependent, greatly diminishing with level. Consequently, as the AC voltage stimulus is reduced (e.g., due to the membrane filter), the DC mechanical response magnitude declines much more precipitously than the $\mathrm{AC}$ mechanical response. Figure $10 \mathrm{dem}-$ onstrates this inherent outcome of such a V-M function in a model AC simulation. DC mechanical components are vanishingly small at low stimulus levels.

Evans et al. (1990, 1991) have reported significant DC mechanical responses at low AC stimulation levels. The superposition of their data (from Evans et al., 1990, their Fig. 2) onto the AC data in Figure $2 A$ indicates that the form of their V-M function in the voltage range shown is remarkably similar to the form obtained in the present study under voltage clamp. This is of interest since their stimulus delivery technique (a partitioning microchamber) differs from the whole-cell technique used here. However, while they may have control over the voltage imposed across the membrane of the $\mathrm{OHC}$, their technique permits neither the control of the resting membrane potential nor the control of the intracellular environment (e.g., $\mathrm{pH}$ ). Calculation of the DC:AC ratio predicted by their V-M function presents essentially the same result as that calculated for the voltage-clamp data reported here. It is surprising, therefore, that they detect a linear modification in both the $\mathrm{AC}$ and DC mechanical components as stimulus magnitude is changed. The inability to control resting potential and/or intracellular environment with the microchamber technique may underlie their observation; for example, the resting potential along the $\mathrm{V}$-M function or $V_{h}$ may be changing as a function of stimulus level. DC responscs nccessarily change when resting voltage shifts relative to $V_{h}$. Relatedly, Evans et al. (1991) presented data that they interpreted to indicate that the DC component was vulnerable to repeated voltage stimulations. These data may

it is very difficult extrapolating to in vivo conditions. It should be noted, however, that $\mathrm{DC}$ mechanical responses of the basilar membrane in vivo, presumably due to the effects of OHCs, have been measured at high sound pressure levels (LePage, 1987). Obviously, it is important to obtain $V_{h}$ estimates in vivo. Since the voltage dependence of nonlinear capacitance in the $\mathrm{OHC}$ is similar to that of the cell's mechanical response (Santos-Sacchi, 1991b), inferences concerning the mechanical response $V_{h}$ may be made from in vivo estimates of voltage-dependent capacitance. 

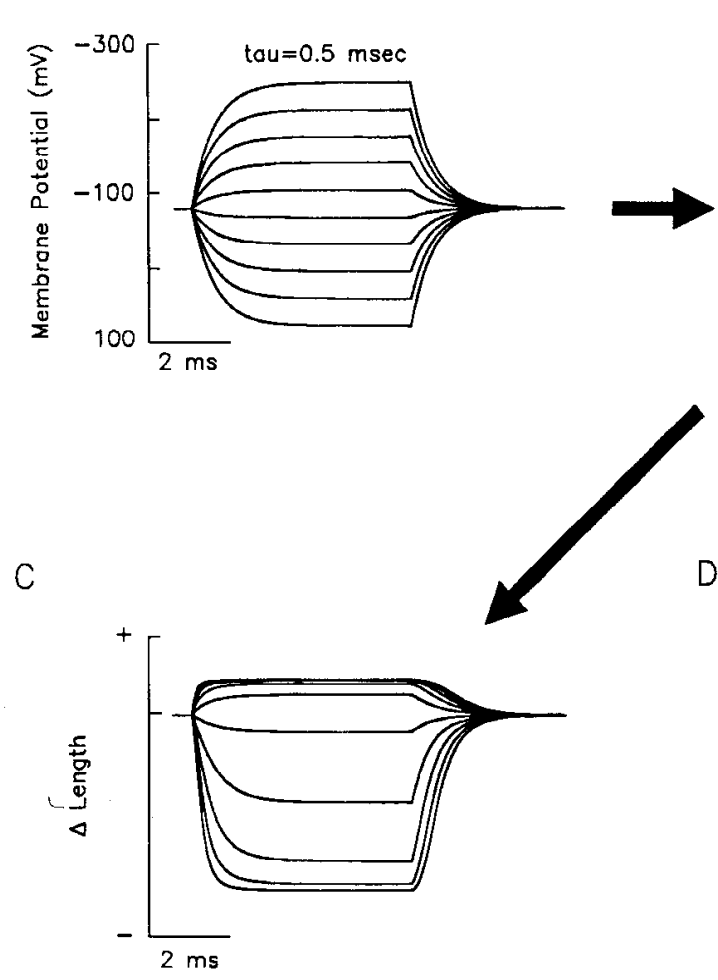

B

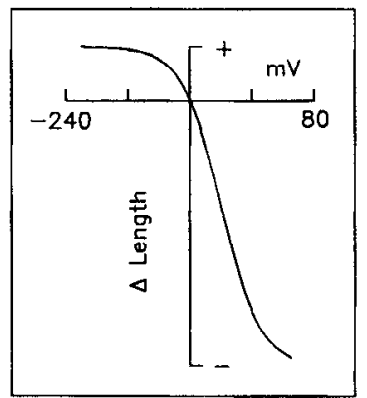

D

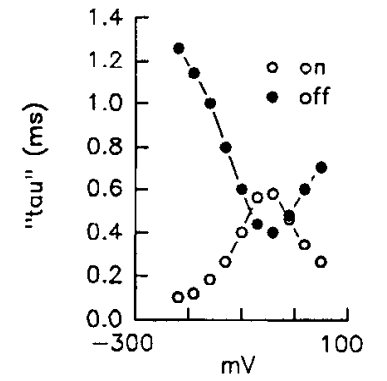

Figure 9. Simulation of voltage step induction of mechanical response in an OHC based on a model input-output V-M function. Filtered voltage steps $(\tau$ $=0.5 \mathrm{msec}$ ) of various magnitudes $(A)$ about the holding potential of $-80 \mathrm{mV}$ were passed through the model $\mathrm{OHC}$ $V$-M function $(B)$ of $V_{h}=-40$ and $b=$ $25 \mathrm{mV}$. The resultant motility responses $(C)$ are governed by the form of the $\mathrm{V}-\mathrm{M}$ function, and the value of the holding potential. The saturating nonlinearity of the V-M function produces apparent level-dependent (step potential) changes in the "time constant" of the mechanical response $(D)$. Time constants ("tau") for on and off responses were determined by noting the time to rise to $63 \%$ or fall to $37 \%$ of the steady state values, respectively. also reflect the effects of a drift of the resting potential or $V_{h}$ of the $\mathrm{OHC}$, and not an induced linearization of the $\mathrm{V}-\mathrm{M}$ function. No induced linearization of a given $\mathrm{V}-\mathrm{M}$ function is observed under whole-cell voltage clamp, where the holding potential is readily maintained and the intracellular environment is highly buffered, even with prolonged saturating voltage stimuli.
The physiological consequence of a level-dependent DC mechanical component is clear. In vivo, for a $15 \mu \mathrm{V}$ AC receptor potential near auditory threshold, it is calculated that the mechanical DC:AC ratio will be less than 0.0004 . Even if the $\mathrm{OHC}$ mechanical response were as great as the largest response we have observed in the midregion of the V-M function $(\sim 30 \mathrm{~nm} /$
A

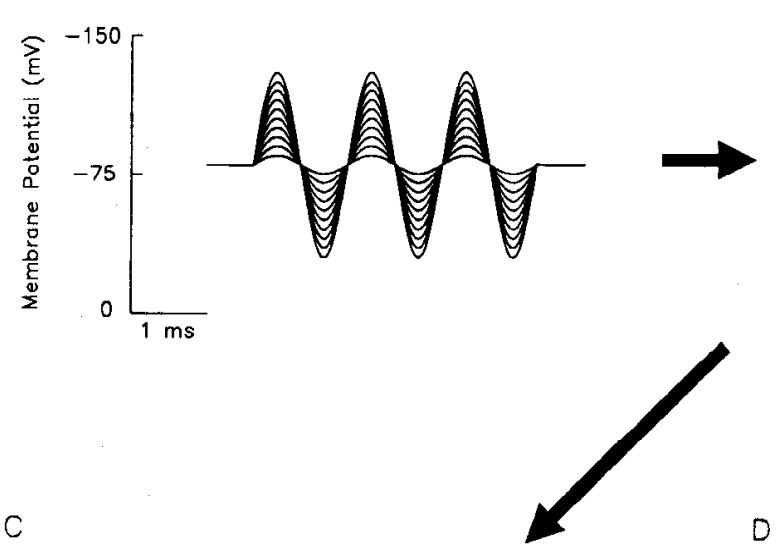

B
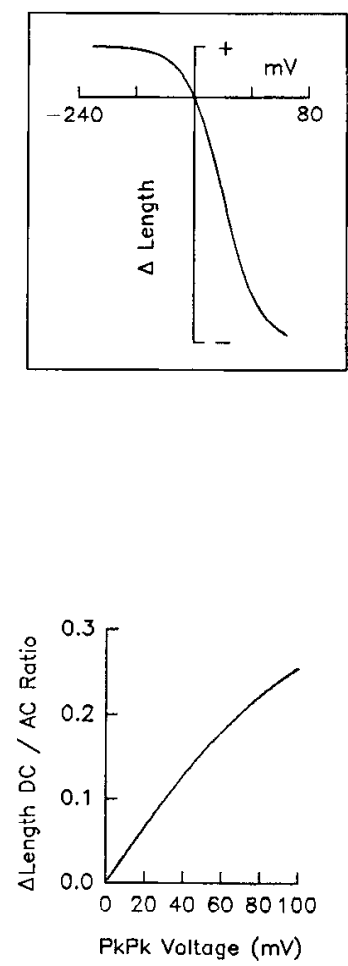

Figure 10. Simulation of voltage sine wave burst induction of $A C$ and $D C$ mechanical responses in an $\mathrm{OHC}$ based on a model input-output V-M function. Voltage sine wave bursts of various magnitudes $(A)$ about the holding potential of $-80 \mathrm{mV}$ were passed through the model OHC V-M function $(B)$ of $V_{h}=-40$ and $b=25 \mathrm{mV}$. The resultant motility responses $(C)$ are governed by the form of the V-M function, and the value of the holding potential. The offset of $V_{h}$ from the holding potential ensures the production of DC responses (difference between baseline and half-PkPk response). A decrease in the amplitude of the driving voltage affects the magnitudes of the $A C$. and $\mathrm{DC}$ responses differently. The DC: AC ratio $(D)$ clearly indicates that the DC response is more susceptible to voltage magnitude alterations. 
$\mathrm{mV}),{ }^{5}$ the DC mechanical response would be $18 \mathrm{fm}$. Clearly, it is difficult to imagine the significance of such $\mathrm{DC}$ displacements when basilar membrane motions at threshold are estimated to be near $350 \mathrm{pm}$ in the guinea pig (Sellick et al., 1982) and 2000 $\mathrm{pm}$ in the chinchilla (Robles et al., 1986). ${ }^{6}$ It is important to note, however, that hair cells are capable of generating DC receptor potentials that are not susceptible to the attenuation effects of the cell's RC time constant (Dallos et al., 1982; Russell and Sellick, 1983). Such DC potentials generated at high acoustic frequencies should induce movements of the OHC. However, whereas IHCs produce significant DC potentials at the characteristic frequency threshold in the high-frequency region of the cochlea, OHCs do not (Russell et al., 1986). Thus, the occurrence of rapid, stimulus related DC mechanical responses that are physiologically significant at auditory threshold is not readily envisioned.

In summary, this report demonstrates the widest mechanical frequency response of the $\mathrm{OHC}$ measured to date, and shows that the mechanical rectification due to the V-M function extends well into the kilohertz range. These results attest to the unique nature of the OHC's motility mechanism among known cellular mechanisms of movement. Nevertheless, the results

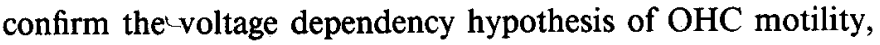
and the limitations that this dependency imposes in vivo remain to be reconciled with current concepts of OHC performance in the high-frequency region of the mammalian inner ear.

\section{References}

Ashmore JF (1987) A fast motile response in guinea-pig outer hair cells: the cellular basis of the cochlear amplifier. J Physiol (Lond) 388: 323-347.

Ashmore JF (1989) Transducer motor coupling in cochlear outer hair cells. In: Mechanics of hearing (Kemp D, Wilson JP, eds), pp 107113. New York: Plenum.

Armstrong CM, Bezanilla F (1973) Currents related to movement of the gating particles of the sodium channels. Nature 242:459-461.

Brown MC, Nuttall AL (1984) Efferent control of cochlear inner hair cell responses in the guinea-pig. J Physiol (Lond) 354:625-646.

Brownell WE, Kachar B (1986) Outer hair cell motility: a possible electro-kinetic mechanism. In: Peripheral auditory mechanisms (Allen JB, Hall JL, Hubbard AE, Neely ST, Tubis A, eds), pp 369-376. New York: Springer.

Brownell WE, Bader CR, Bertrand D, de Ribaupierre Y (1985) Evoked mechanical responses of isolated cochlear outer hair cells. Science 227:194-196.

Clark BA, Hallworth R, Evans BN (1990) Calibration of photodiode measurements of cell motion by a transmission optical lever method. Pfluegers Arch 41 5:490-493.

Cody AR, Russell IJ (1985) Outer hair cells in mammalian cochlea and noise-induced hearing loss. Nature 315:662-665.

Dallos P, Harris D (1978) Properties of auditory nerve responses in absence of outer hair cells. J Neurophysiol 41:365-383.

Dallos P, Santos-Sacchi J, Flock $\AA$ (1982) Intracellular recordings from outer hair cells. Science 218:582-584.

\footnotetext{
${ }^{5}$ The use of the $\sim 30 \mathrm{~nm} / \mathrm{mV}$ figure (from Santos-Sacchi and Dilger, 1988) is unrealistic since the OHC normally rests at a potential of about $-70 \mathrm{mV}$ and the mechanical response slope at this region of the V-M function is far smaller than the maximum slope (see Fig. $2 B$ ).

${ }^{6}$ The inherent linearization of the $\mathrm{OHC}$ mechanical response at low stimulation levels was alluded to previously (Santos-Sacchi, 1989) but was deemed incorrect by Evans et al. (1991) based on their measures of large DC mechanical components at low stimulus levels. They suggested, based on their measures, that the nonlinearity of $\mathrm{OHC}$ motility may be an important source of cochlear nonlinearity. However, considering the present findings, it remains questionable whether their suggestion is valid at threshold in the high-frequency regions of the cochlea.
}

Dallos P, Evans BN, Hallworth R (1991a) On the nature of the motor element in cochlear outer hair cells. Nature 350:155-157.

Dallos P, Hallworth R, Evans BN (1991b) Stochastic theory of outer hair cell electromotility. In: Auditory physiology and perception. Proceedings of the 9th International Symposium on Hearing, Carcans, France, June 9-14, 1991.

Evans BN, Dallos P, Hallworth R (1989) Asymmetries in motile responses of outer hair cells in simulated in vivo conditions. In: Mechanics of hearing (Kemp D, Wilson JP, eds), pp 205-206. New York: Plenum.

Evans BN, Hallworth R, Dallos P (1990) The nonlinearity of outer hair cell motility: implications for cochlear physiology and pathology. In: The mechanics and biophysics of hearing (Dallos P, Geisler CD, Matthews JW, Ruggero MA, Steele CR, eds), pp 61-68. Berlin: Springer.

Evans BN, Hallworth R, Dallos P (1991) Outer hair cell electromotility: the sensitivity and vulnerability of the DC component. Hearing Res 52:288-304

Geisler CD, Shan X (1990) A model for cochlear vibrations based on feedback from motile outer hair cells. In: The mechanics and biophysics of hearing (Dallos P, Geisler CD, Matthews JW, Ruggero MA, Steele CR, eds), pp 86-95. Berlin: Springer.

Harrison RV, Evans EF (1979) Cochlear fiber responses in guinea pigs with well defined cochlear lesions. Scand Audiol [Suppl]9:83-92.

Hubbard AE, Mountain DC (1990) Hair cell forward and reverse transduction: differential suppression and enhancement. Hear Res 43: 269-272.

Hudspeth AJ (1989) How the ear's works work. Nature 341:397-404.

Iwasa KH, Kachar B (1989) Fast in vitro movement of outer hair cells in an external electric field: effect of digitonin, a membrane permeabilizing agent. Hear Res 40:247-254.

LePage EL (1987) Frequency-dependent self-induced bias of the basilar membrane and its potential for controlling sensitivity and tuning in the mammalian cochlea. J Acoust Soc Am 82:139-154.

Marty A, Neher E (1983) Tight-seal whole-cell recording. In: Singlechannel recording (Sakmann B, Neher E, eds), pp 107-122. New York: Plenum.

McLaughlin S, Mathias RT (1985) Electro-osmosis and the reabsorption of fluid in renal proximal tubules. J Gen Physiol 85:699-728.

Robles L, Ruggero MA, Rich NC (1986) Basilar membrane mechanics at the base of the chinchilla cochlea. I. Input-output functions, tuning curves, and response phases. J Acoust Soc Am 80:1364-1374.

Robles L, Ruggero MA, Rich NC (1991) Two-tone distortion in the basilar membrane of the cochlea. Nature 349:413-414.

Ruggero MA, Rich NC (1991) Furosemide alters organ of Corti mechanics: evidence for feedback of outer hair cells upon the basilar membrane. J Neurosci 11:1057-1067.

Russell IJ, Sellick PM (1983) Low frequency characteristics of intracellularly recorded receptor potentials in mammalian hair cells. $J$ Physiol (Lond) 338:179-206.

Russell IJ, Cody AR, Richardson GP (1986) The responses of inner and outer hair cells in the basal turn of the guinea-pig cochlea and in the mouse cochlea grown in vitro. Hear Res 22:199-216.

Spoendlin H (1988) Neural anatomy of the inner ear. In: Physiology of the ear (Jahn A, Santos-Sacchi J, eds), pp 201-219. New York: Raven.

Santos-Sacchi J (1989) Asymmetry in voltage dependent movements of isolated outer hair cells from the organ of Corti. J Neurosci 9:29542962.

Santos-Sacchi J (1990) Fast outer hair cell motility: how fast is fast? In: The mechanics and biophysics of hearing (Dallos P, Geisler CD, Matthews JW, Ruggero MA, Steele CR, eds), pp 69-75. Berlin: Springer.

Santos-Sacchi J (1991a) Relations between DC and AC mechanical responses of the outer hair cell. Paper presented at the 121 st meeting of the Acoustical Society of America, Houston, TX, November.

Santos-Sacchi J (1991b) Reversible inhibition of voltage-dependent outer hair cell motility and capacitance. J Neurosci 11:3096-3110.

Santos-Sacchi J, Dilger JP (1988) Whole cell currents and mechanical responses of isolated outer hair cells. Hearing Res 35:143-150.

Sellick PM, Patuzzi R, Johnstone BM (1982) Measurement of basilar membrane motion in the guinea pig using the Mossbauer technique. J Acoust Soc Am 72:131-141. 